Atmos. Chem. Phys., 17, 14105-14118, 2017

https://doi.org/10.5194/acp-17-14105-2017

(C) Author(s) 2017. This work is distributed under

the Creative Commons Attribution 3.0 License.

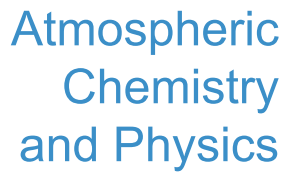

(c) (i)

\title{
Partitioning the primary ice formation modes in large eddy simulations of mixed-phase clouds
}

\author{
Luke B. Hande and Corinna Hoose \\ Institute of Meteorology and Climate Research, Karlsruhe Institute of Technology, Karlsruhe, Germany \\ Correspondence to: Luke B. Hande (luke.hande@kit.edu) and Corinna Hoose (corinna.hoose@kit.edu)
}

Received: 26 May 2017 - Discussion started: 31 May 2017

Revised: 9 October 2017 - Accepted: 13 October 2017 - Published: 27 November 2017

\begin{abstract}
State-of-the-art aerosol-dependent parameterisations describing each heterogeneous ice nucleation mode (contact, immersion, and deposition ice nucleation), as well as homogeneous nucleation, were incorporated into a large eddy simulation model. Several cases representing commonly occurring cloud types were simulated in an effort to understand which ice nucleation modes contribute the most to total concentrations of ice crystals. The cases include a completely idealised warm bubble, semi-idealised deep convection, an orographic cloud, and a stratiform case. Despite clear differences in thermodynamic conditions between the cases, the results are remarkably consistent between the different cloud types. In all the investigated cloud types and under normal aerosol conditions, immersion freezing dominates and contact freezing also contributes significantly. At colder temperatures, deposition nucleation plays only a small role, and homogeneous freezing is important. To some extent, the temporal evolution of the cloud determines the dominant freezing mechanism and hence the subsequent microphysical processes. Precipitation is not correlated with any one ice nucleation mode, instead occurring simultaneously when several nucleation modes are active. Furthermore, large variations in the aerosol concentration do affect the dominant ice nucleation mode; however, they have only a minor influence on the precipitation amount.
\end{abstract}

\section{Introduction}

Ice crystals in the atmosphere can form spontaneously through homogeneous nucleation, which becomes increasingly probable at temperatures lower than $-35^{\circ} \mathrm{C}$ (Koop and Murray, 2016). At warmer temperatures an ice nucleating particle (INP) is required to initiate freezing. Although INPs represent a small fraction of all atmospheric aerosols (Rogers et al., 1998), they have a disproportionately large influence on mixed-phase cloud microphysics (DeMott et al., 2010). Therefore modelling ice microphysical processes accurately is necessary to correctly model clouds and the myriad subsequent processes influenced by clouds.

Several pathways have been identified through which ice nucleation in the atmosphere can take place (Vali et al., 2015). Deposition nucleation occurs at cold temperatures, where water vapour is deposited as ice directly onto an aerosol particle. Immersion and condensation freezing require the particle to be immersed in super-cooled liquid water, after which freezing occurs. Contact freezing occurs when an aerosol particle comes into contact with a supercooled droplet, which subsequently initiates freezing. A similar mechanism called inside-out freezing has been identified, where a immersed particle comes into contact with the water-air interface, which initiates freezing (Durant and Shaw, 2005). Contact freezing and inside-out freezing have long been hypothesised to be important in areas of evaporation (Wang et al., 1978). Indeed, recent results from a modelling study support this idea (Hande et al., 2017).

Kanji et al. (2017) present a detailed overview of the latest ice nucleation research. Ice nucleation can be studied in a wide variety of ways (Cziczo et al., 2016), including under tightly controlled conditions in the laboratory. Recent reviews of laboratory experiments (Hoose and Möhler, 2012; Murray et al., 2012) highlight the tendency for much attention to be directed towards identifying and quantifying the ice nucleating ability of different aerosols species in each nucleation mode separately. These laboratory studies do little to 
elucidate the relative importance of these modes, so their atmospheric relevance is poorly understood.

Ladino Moreno et al. (2013) provide a review of experimental studies investigating contact nucleation and go so far as to suggest it could dominate over immersion freezing for some aerosol species. Given that laboratory results suggest it is an efficient ice formation mechanism, these authors specifically pose questions as to whether this also holds true in simulations. However in more recent experiments, Nagare et al. (2016) could not confirm a general enhancement in contact freezing compared to immersion freezing.

Modelling results from Cui et al. (2006) show that immersion freezing is the dominant pathway through which ice is formed, with contact playing little to no role. In this study, deposition nucleation was significant in the early stages of cloud development. Phillips et al. (2007) used a model to also show that contact freezing has little impact on heterogeneous ice nucleation in deep convective clouds. An analysis of trajectories from a dust dominated region showed air parcels commonly pass through ice-saturated, but water subsaturated, regions, where deposition nucleation could occur (Wiacek and Peter, 2009). Later, Hoose et al. (2010) showed that immersion freezing dominates INP production, and in contrast to the previous modelling studies, contact freezing played an important role in their simulations. Spichtinger and Cziczo (2010) used a model to show there is competition between heterogeneous and homogeneous ice nucleation, which is influenced by thermodynamic and microphysical conditions.

In situ and remote sensing observations have also been employed to study ice nucleation under atmospheric conditions. Ansmann et al. (2009) observed altocumulus clouds which almost always had liquid water at cloud top, suggesting deposition nucleation plays little role. This has been supported by observations in cases of lee-wave clouds (Field et al., 2012) and stratiform clouds (De Boer et al., 2011; Westbrook and Illingworth, 2011), suggesting either immersion or contact freezing dominates ice production.

A recent global analysis of satellite observations (CarroCalvo et al., 2016) indicates there are low cloud glaciation temperatures in areas of deep convection, not only in the tropics but also extending to the mid-latitudes. This suggests homogeneous freezing and/or deposition nucleation are important. The warm ice clouds analysed in their study, on the other hand, were associated with stratiform cloud systems, and the authors pose the question of the role that dynamics play in initiating early cloud glaciation.

Since immersion and contact freezing require the presence of liquid water, they are thought to be the dominant ice formation pathway in mixed phase clouds. The above studies (Phillips et al., 2007; Ansmann et al., 2009; Hoose et al., 2010; De Boer et al., 2011) seem to suggest this is the case; however, there is still considerable uncertainty. In addition, there is little consensus on whether deposition nucleation or homogeneous freezing contributes significantly to ice production at cirrus temperatures.

A further complication arises since ice nucleation is clearly influenced by the ambient environmental conditions, and as such the dominant mode could depend on the cloud type. This paper aims to help clarify, in a systematic way, which ice nucleation modes dominate for various cloud types found over continental regions. The contribution of each mode to precipitation will also be considered. The cases studied here are a warm bubble, semi-idealised deep convection, idealised orographic, and a stratiform cloud, and hence cover a variety of thermodynamic conditions.

\section{Model description}

The non-hydrostatic regional weather forecasting model COSMO (COnsortium for Small-scale MOdelling) (Schättler et al., 2008) version 5.01 was run at high resolution of $8.9 \times 10^{-4 \circ}(\approx 100 \mathrm{~m})$. This scale is small enough to resolve energy-containing turbulence (Barthlott and Hoose, 2015). The two-moment cloud microphysics scheme of Seifert and Beheng (2006) was used, which uses the supersaturation to define a power law, from which cloud condensation nuclei (CCN) concentrations representative of continental conditions are calculated. The droplet size distribution was calculated from the model diagnosed cloud liquid water content and droplet number concentration in every grid box, assuming a modified gamma distribution, with parameters defined in Seifert and Beheng (2006), for droplets in the size range 1 to $535 \mu \mathrm{m}$. Figure 1 shows the spatial and temporal mean cloud droplet size distribution for each case investigated. These cases are described in detail in the next section.

Recent work has made significant progress in the development of detailed parameterisations for deposition nucleation, immersion freezing, and contact freezing (Niemand et al., 2012; Tobo et al., 2013; DeMott et al., 2010, 2015; Hiranuma et al., 2014; Steinke et al., 2015; Diehl and Mitra, 2015; Ullrich et al., 2017; Hande et al., 2017). These parameterisations were developed either from observations or theory, and are representative of nucleation on a variety of aerosol species.

In this study, the Steinke et al. (2015) parameterisation for deposition nucleation on Arizona test dust (ATD) was used. This parameterisation is a function of supersaturation with respect to ice, and temperature, and is active from 226 to $250 \mathrm{~K}$. Niemand et al. (2012) was employed to describe immersion freezing, which depends on temperature, and acts between 237 and $261 \mathrm{~K}$. In these two parameterisations, particle surface area also plays a role through the use of the ice nucleation active surface site (INAS) densities. Comparing these two parameterisations to recently developed formulations by Ullrich et al. (2017) shows good agreement for immersion freezing and lower deposition nucleation efficiency for desert dust compared to ATD. This provides some mea- 


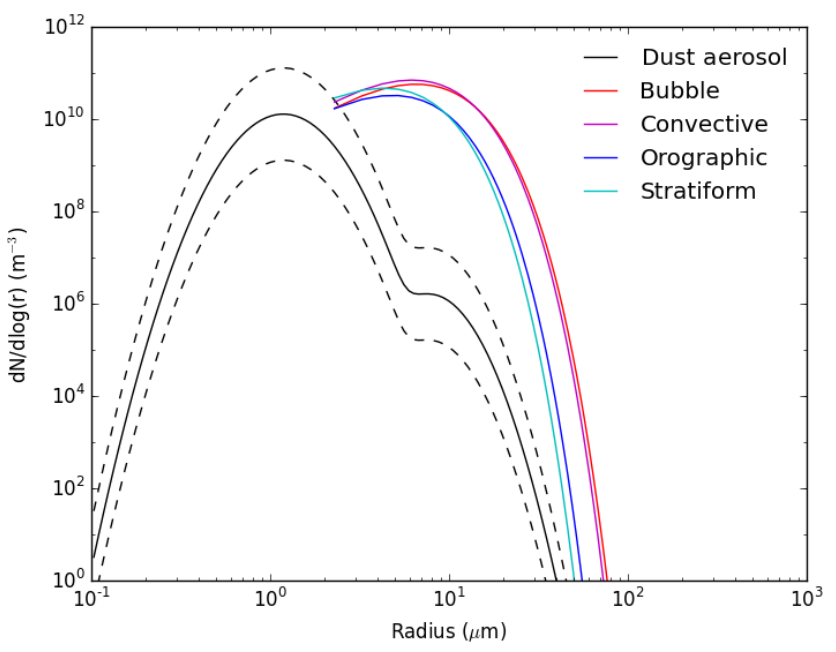

Figure 1. Prescribed dust aerosol size distribution, and derived mean cloud droplet size distribution for all cases. Dashed lines indicate dust aerosol size distribution for sensitivity studies.

sure of confidence in the reliability of the parameterisations used here.

The study of Hande et al. (2017) was used for contact freezing with generic dust aerosols. This parameterisation is a function of aerosol and droplet size and number concentration, relative humidity, temperature, and electrical charges, and is active between 240 and 268 K. Finally, theoretical expressions of the homogeneous nucleation rate by Jeffery and Austin (1997) were used to describe homogeneous freezing.

A two-mode log-normal dust aerosol size distribution was used, as shown in Fig. 1, covering particle sizes from 0.1 to $100 \mu \mathrm{m}$, which is based on observations from Jungfraujoch research station (M. Niemand, personal communication, 2015) (mode 1: $N=0.015 \times 10^{6} \mathrm{~m}^{-3}, \quad \mu=1.355 \times 10^{-6} \mathrm{~m}, \quad \sigma=1.443 ;$ mode 2: $\quad N=0.00001 \times 10^{6} \mathrm{~m}^{-3}, \quad \mu=8.518 \times 10^{-6} \mathrm{~m}$, $\sigma=1.358$ ). Aerosol concentrations at sizes larger than about $30 \mu \mathrm{m}$ are small enough as to be considered zero. The upper bound in the aerosol size distribution is only for mathematical convenience. The dust aerosol concentrations are constant in the vertical dimension throughout the simulation. Model results suggest that dust aerosols are relatively constant in the vertical dimension, with only a $25 \%$ decrease in dust aerosol number concentrations over Germany during summer between the low levels and the tropopause (Hande et al., 2015).

The aerosols are not removed by precipitation or sedimentation in the model. This simplification is not expected to have a significant effect on the formation of INPs. The maximum number concentration of aerosols is orders of magnitude larger than the maximum INP concentrations, as shown later in this paper. Therefore, any removal of aerosols will make a very small difference to the total number concentration. Furthermore, in the case of convectively or orograph- ically forced clouds, entrainment of new aerosols into the cloud adds a source of aerosols to off-set their removal.

Hande et al. (2015) show that the 5th and 95th percentiles of dust number concentrations are representative of low and high dust concentrations. These concentrations are often more than an order of magnitude smaller and larger than the median, depending on the season. The dust aerosol properties used in this study correspond roughly to the properties during summer from Hande et al. (2015), during which concentrations and aerosol sizes are the lowest throughout the year. In order to investigate the sensitivity of ice nucleation to the aerosol size distribution, two additional aerosol size distributions are defined in Fig. 1, shown as the dashed lines. Here, the total number concentration of both modes was modified by factors of 10 and 0.1 , which simulate high and low dust aerosol number concentrations. These sensitivity studies are analysed with a focus on the resulting partitioning into the different ice nucleation modes, e.g. the role of homogeneous versus heterogeneous ice nucleation.

The aerosol and droplet distributions were divided into 10 bins, over which the integration for the parameterisations was performed. The immersion- and contact-freezing parameterisations are only applied to cloud droplets. Since rain drops collect many particles through collision-coalescence they may be important for freezing in the immersion mode, depending on cloud type (Paukert et al., 2017). However simple parameterisations for this process do not exist, limiting applicability of rain freezing through the immersion mode. Furthermore, Niehaus and Cantrell (2015) show that these deliquesced aerosol particles can initiate additional contact freezing.

Immersion freezing acts only on the immersed dust aerosols, and contact freezing acts on the interstitial aerosols. The segregation of immersed and interstitial aerosols is treated simplistically in this work, where the ratio of these quantities is pre-defined. In these simulations, $50 \%$ of the total number of dust aerosols are defined to be interstitial and hence available for contact freezing, and the remaining $50 \%$ is defined to be immersed and available for immersion freezing. This is not necessarily a realistic assumption, but it allows the relative concentrations of immersion and contact INPs to be compared independent of this assumption, since differences in INP concentrations will not be due to differences in aerosol concentrations available for nucleation in a given mode. While some observations support a roughly equal split of dust particles into interstitial and immersed aerosol (Li et al., 2011), we expect this assumption to overestimate the fraction of interstitial dust in conditions where aerosol processing during long-range transport or high supersaturations increase the $\mathrm{CCN}$ activation of dust particles $\mathrm{Ku}-$ mar et al., 2011). Finally, depletion of immersed aerosols is not taken into account in these simulations, which has been shown to cause an overestimate of the ice crystal concentrations by a factor of 2 for an Arctic stratocumulus cloud (Paukert and Hoose, 2014). 
(a)

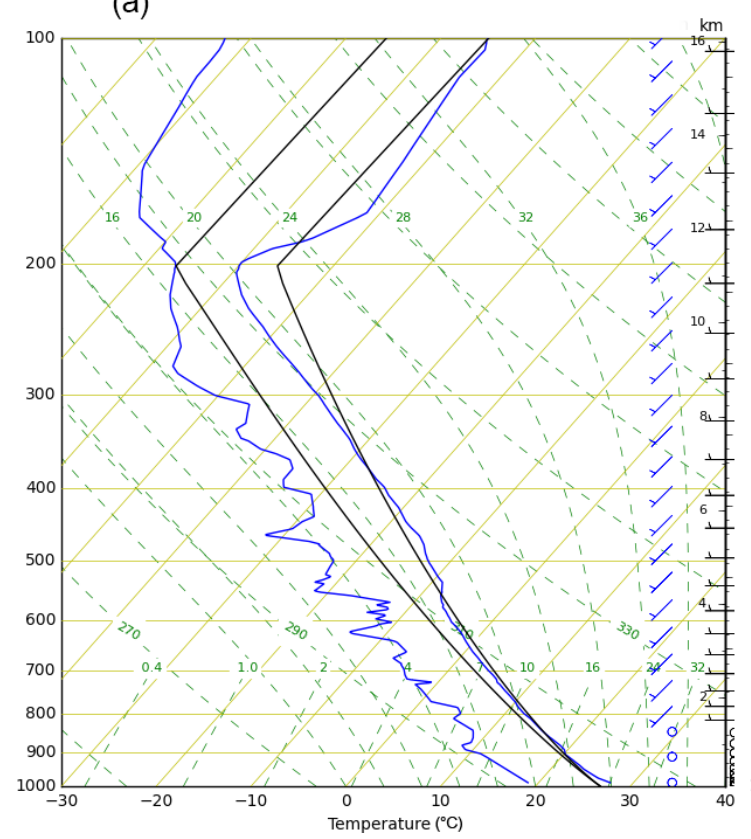

(b)

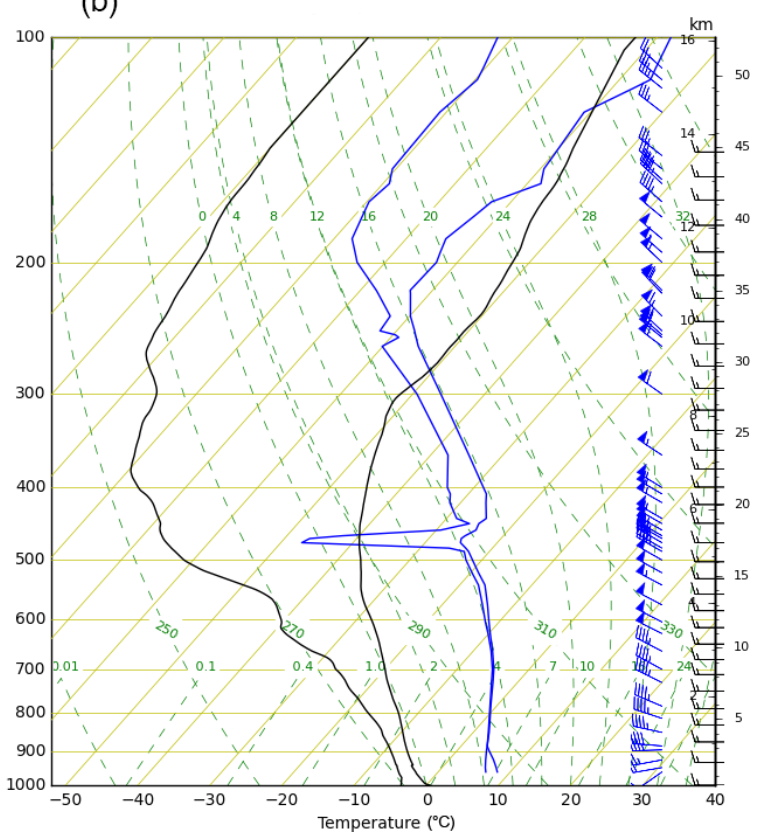

Figure 2. Thermodynamic sounding used to initialise the cases. (a) Idealised heat bubble (black) and semi-idealised deep convective (blue). (b) Orographic (black) and stratiform (blue).

\section{Case study description}

Ice nucleation is influenced by ambient environmental conditions; therefore, in order to systematically study the relative contribution of each mode, a distinction between cloud types must be made. In this section, the model configurations for two cases of convection, an idealised orographic cloud and a stratiform cloud are described.

Since deep convective clouds span temperature ranges relevant for warm and cold cloud microphysics, including into the homogeneous nucleation regime, two cases will be investigated here: a fully idealised warm bubble case, and a semiidealised cloud. Starting with the former, the thermodynamic profile described in Weisman and Klemp (1982) was used to initialise the simulation, shown in the left panel of Fig. 2 as the black lines. A 3-D temperature disturbance of $1.5 \mathrm{~K}$, with radius of $10 \mathrm{~km}$, was placed in the centre of the domain at a height of $1.4 \mathrm{~km}$. In total, 100 vertical levels, with $600 \times 600$ grid cells horizontally, were used, and the time step was $1 \mathrm{~s}$ for the duration of the $4 \mathrm{~h}$ simulation.

The semi-idealised deep convective cloud represents a more realistic simulation of convection, and provides an interesting comparison with the previous idealised heat bubble. A detailed description of the model configuration for this case appears in Hande et al. (2017) and is summarised here. A real sounding with a convective available potential energy (CAPE) of $1889 \mathrm{~J} \mathrm{~kg}^{-1}$ was used to initialise the simulation, and realistic topography was specified at each grid point, as shown in Fig. 6 of Hande et al. (2017). The topography represents the region near Jülich, in western Ger- many, with mountains reaching up to $560 \mathrm{~m}$ in the southwest of the domain. A total of 100 vertical levels were used, and $600 \times 600$ grid cells horizontally, with a time step of $2 \mathrm{~s}$ for the duration of the $9 \mathrm{~h}$ simulation.

To initialise the orographic mixed-phase cloud case, an idealised bell-shaped hill was used along with a real sounding, shown in the right panel of Fig. 2 as the black lines. The hill has a maximum height of $800 \mathrm{~m}$ and a half-width of $15 \mathrm{~km}$. In the longitudinal direction, 1441 grid points were used, and 271 in the latitudinal direction, with 100 vertical levels. A time step of $1 \mathrm{~s}$ was used for the duration of the $4 \mathrm{~h}$ simulation.

The final case to be investigated is a stratiform cloud, which was initialised from a real sounding from central Germany during winter, shown in the right panel of Fig. 2 as the blue lines. A smaller domain with $400 \times 400$ horizontal grid points was used, again with 100 vertical levels. In this case, the horizontal wind speed was artificially increased by a factor of 1.5 in the lowest $5.5 \mathrm{~km}$, in order to increase the dynamical forcing enough to activate cloud droplets through shear-driven turbulence in the boundary layer. Due to the higher wind speeds in this simulation, a shorter time step of $0.5 \mathrm{~s}$ was used for the $9 \mathrm{~h}$ simulation. All investigated cases employed fully periodic boundary conditions.

\section{Spatial distribution of INPs}

In this section the spatial distribution of INPs in each mode will be analysed, along with the cloud droplet properties. 
(a)

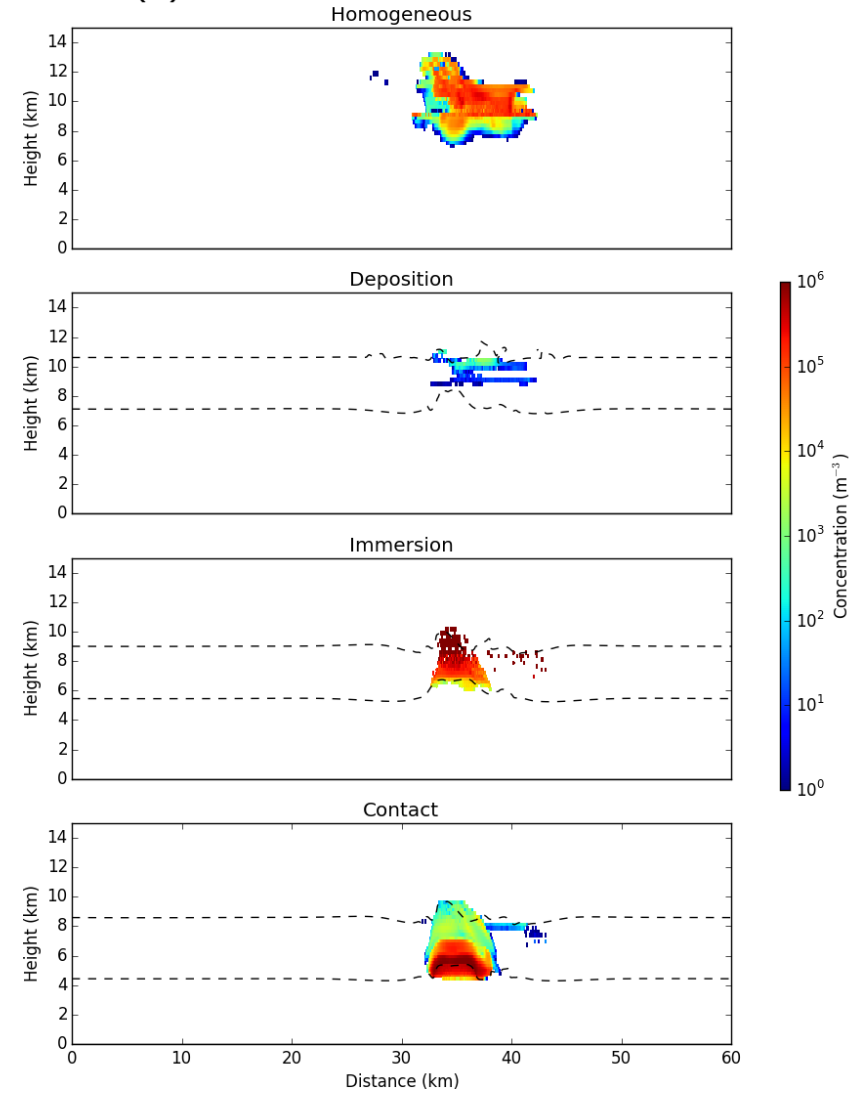

(b)
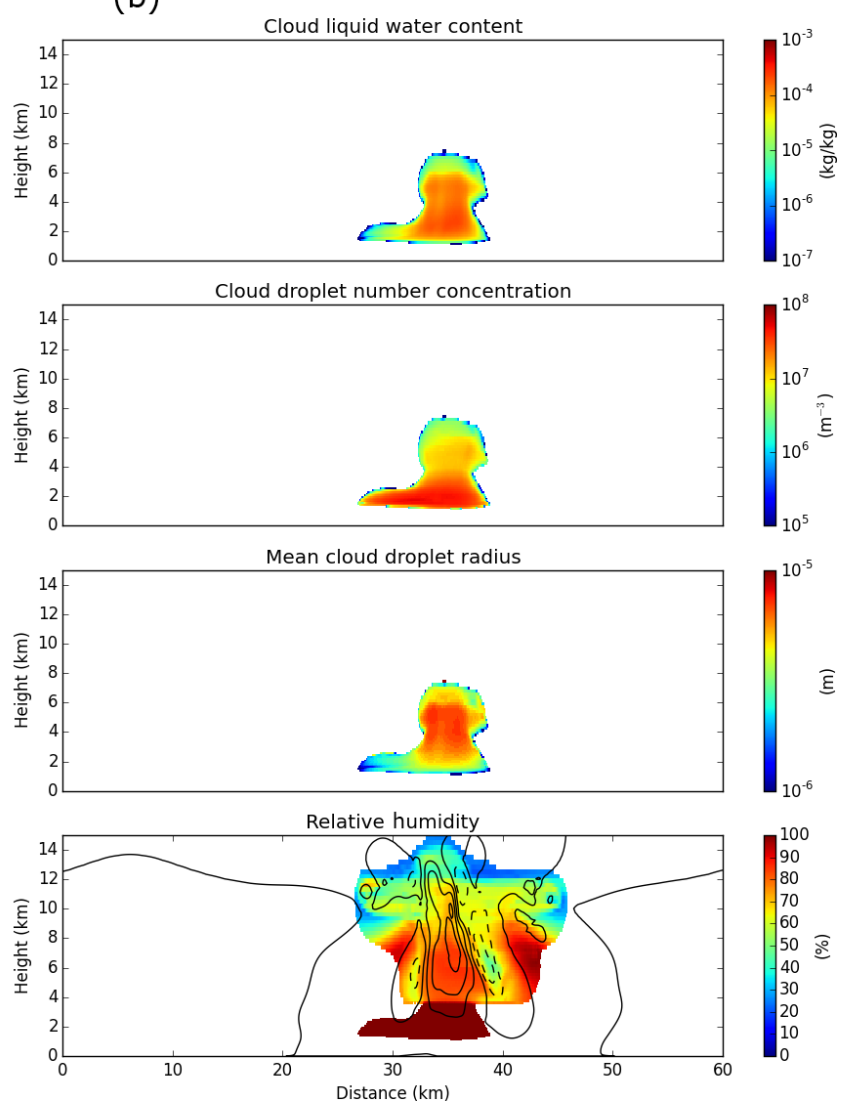

Figure 3. Domain mean horizontal cross section of INP number concentrations in each mode (a) and cloud droplet properties (b) for the heat bubble convective cloud at $0.5 \mathrm{~h}$ into the simulation for normal dust concentrations. Dashed horizontal lines represent the temperature limits of the parameterisations. Contours represent the sign of the vertical velocity (solid: positive; dashed: negative).

Contact-freezing INPs are parameterised in terms of a rate, so the number concentrations are obtained by multiplying by the time step of the simulation. All diagrams in this section are domain mean horizontal cross sections taken at a particular time step indicated in the figure captions, where the mean is taken over all latitudes. As described in the Sect. 2, cloud droplet size was calculated from cloud liquid water content and number concentration, assuming a gamma distribution at each grid point. The mode in the cloud droplet radius distribution which is shown in the following diagrams is simply the radius at which the maximum in the cloud droplet size distribution occurred, and the variance and skewness of the distributions are not represented.

Starting with the idealised heat bubble, Fig. 3 shows the concentrations of INPs (left panels), along with the cloud droplet properties (right panels) at $0.5 \mathrm{~h}$ into the simulation. Immersion and contact freezing both contribute significantly at warmer temperatures, and homogeneous nucleation is a major contributor at colder temperatures. Deposition nucleation, however, is limited to low concentrations occurring over a narrow temperature range.
Looking closer at immersion freezing, there is a trend of higher INP concentrations at colder temperatures. This should be expected since, according to this parameterisation, there is an inverse exponential relationship between INAS density and temperature.

Contact freezing, on the other hand, shows the opposite trend. Although the contact-freezing efficiency also increases exponentially with decreasing temperature, droplet properties have a larger influence on INP concentrations, as discussed in Hande et al. (2017). The highest concentrations in the contact mode occur at around $6 \mathrm{~km}$, co-located with the maximum in cloud droplet size. At colder temperatures above this height, the size and number concentration of cloud droplets is lower, reducing the effectiveness of contact freezing since the contact-freezing collection kernel strongly favours large aerosol-large droplet interactions.

The final panel in Fig. 3 shows the in-cloud relative humidity with respect to liquid water. On both sides of the central updraught, indicated by the solid contours, there are regions of downdraughts, shown by the dashed contours. This results in lower relative humidity, which acts to suppress the formation of INPs. 
(a)
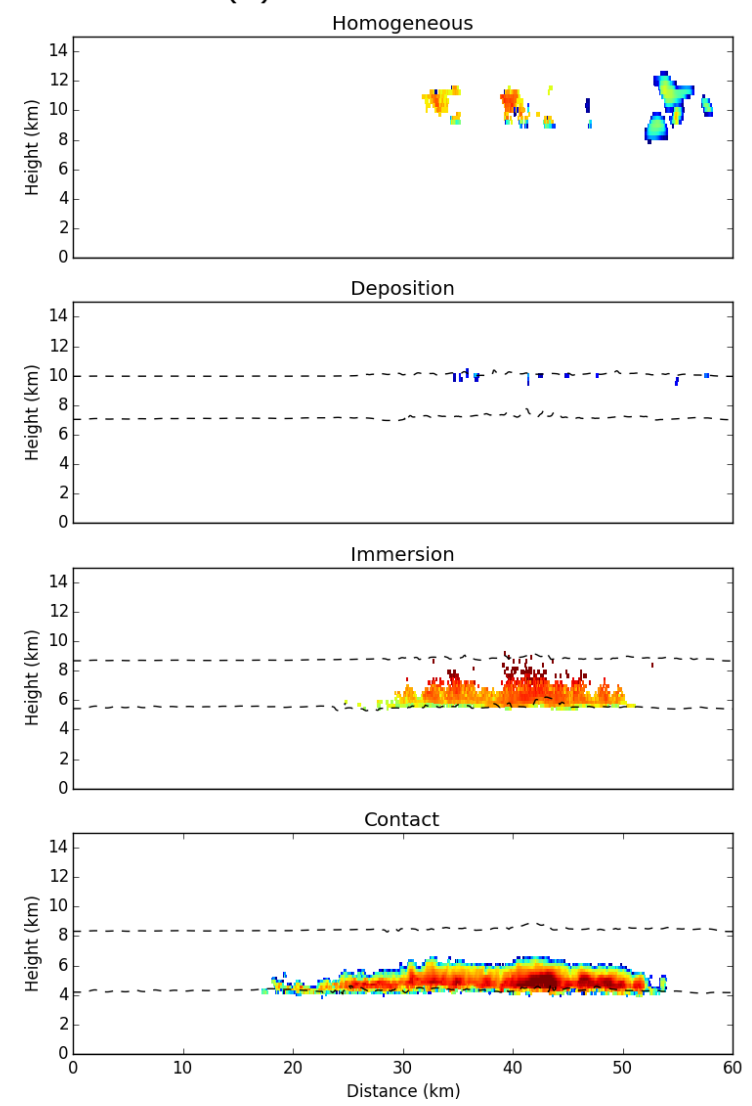

(b)
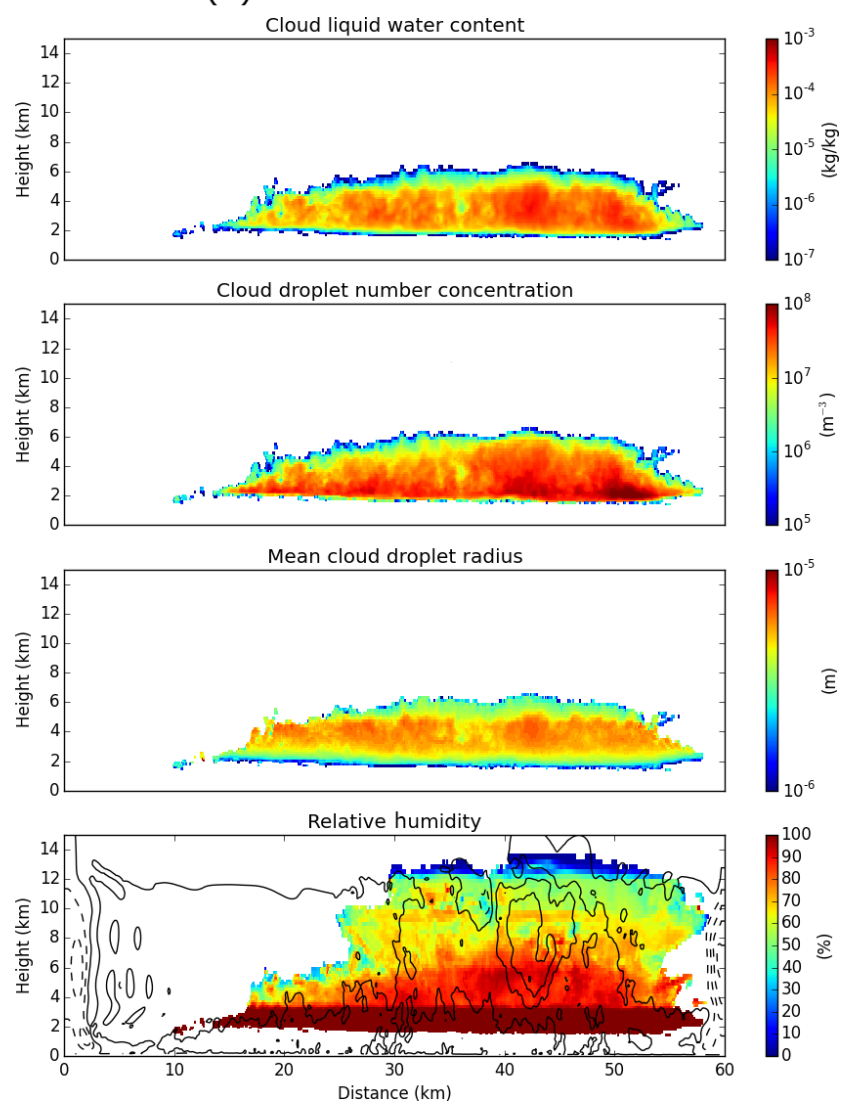

Figure 4. Domain mean horizontal cross section of INP number concentrations in each mode (a) and cloud droplet properties (b) for the semiidealised deep convective cloud at $4 \mathrm{~h}$ into the simulation for normal dust concentrations. Dashed horizontal lines represent the temperature limits of the parameterisations. Contours represent the sign of the vertical velocity (solid: positive; dashed: negative).

The results for the semi-idealised deep convective case, shown in Fig. 4, are remarkably consistent with the previous case: immersion and contact freezing both dominate, and homogeneous nucleation contributes the most at cold temperatures. Furthermore, the trend in immersion and contact INPs is the same as the idealised heat bubble.

The added complexity in this case highlights an interesting feature of the contact parameterisation employed in this study. Looking at the relative humidity, between about 16 and $26 \mathrm{~km}$ in the horizontal direction, the relative humidity is less than approximately $80 \%$. Despite this, the concentrations of contact INPs are as high as $10^{5} \mathrm{~m}^{-3}$. That INPs can still form in this environment is a consequence of the phoretic forces (Wang et al., 1978) increasing the collision efficiency between aerosols and cloud droplets in lowerhumidity regions. The lifetime of droplets can be calculated using Eq. (3.14) from Houze (2014), ignoring curvature effects and assuming pure spherical droplets. A $10 \mu \mathrm{m}$ droplet exposed to relative humidity of $80 \%$ at $260 \mathrm{~K}$ should completely evaporate in $5.7 \mathrm{~s}$, decreasing to $2.8 \mathrm{~s}$ at relative humidity of $60 \%$. Furthermore, Hande et al. (2017) show that in a deep convective cloud, droplets warmer than about $260 \mathrm{~K}$ can have number concentrations up to $10^{8} \mathrm{~m}^{-3}$. These two points indicate there should be high numbers of droplets available for collisions within a few seconds before evaporating. Finally, another interesting feature of the deep convective case is the high levels of variability in INP concentrations along isotherms. This variability is attributable to the large influence of relative humidity and droplet properties on the contact-freezing rate.

The orographic cloud case is shown in Fig. 5. Here, homogeneous freezing and deposition nucleation play no role in ice formation, since the cloud top does not reach sufficiently cold temperatures, and immersion INP concentrations are significantly higher than contact INP concentrations. Immersion INP concentrations are more or less homogeneously distributed throughout the cloud, and the highest concentrations in the contact mode are co-located with high concentrations of large cloud droplets. In the lee of the hill there is a downdraught, indicated by the dashed contours. As was seen in the first case, this reduces the relative humidity and suppresses ice formation. 
(a)

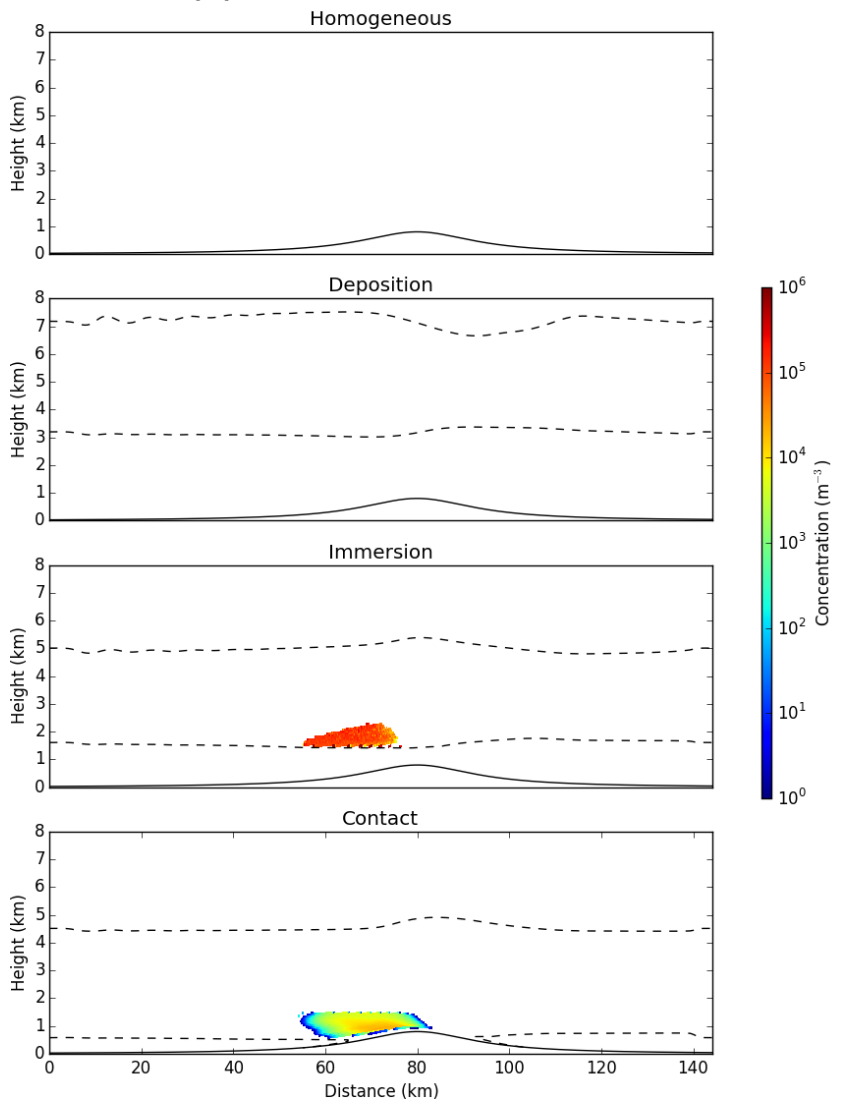

(b)
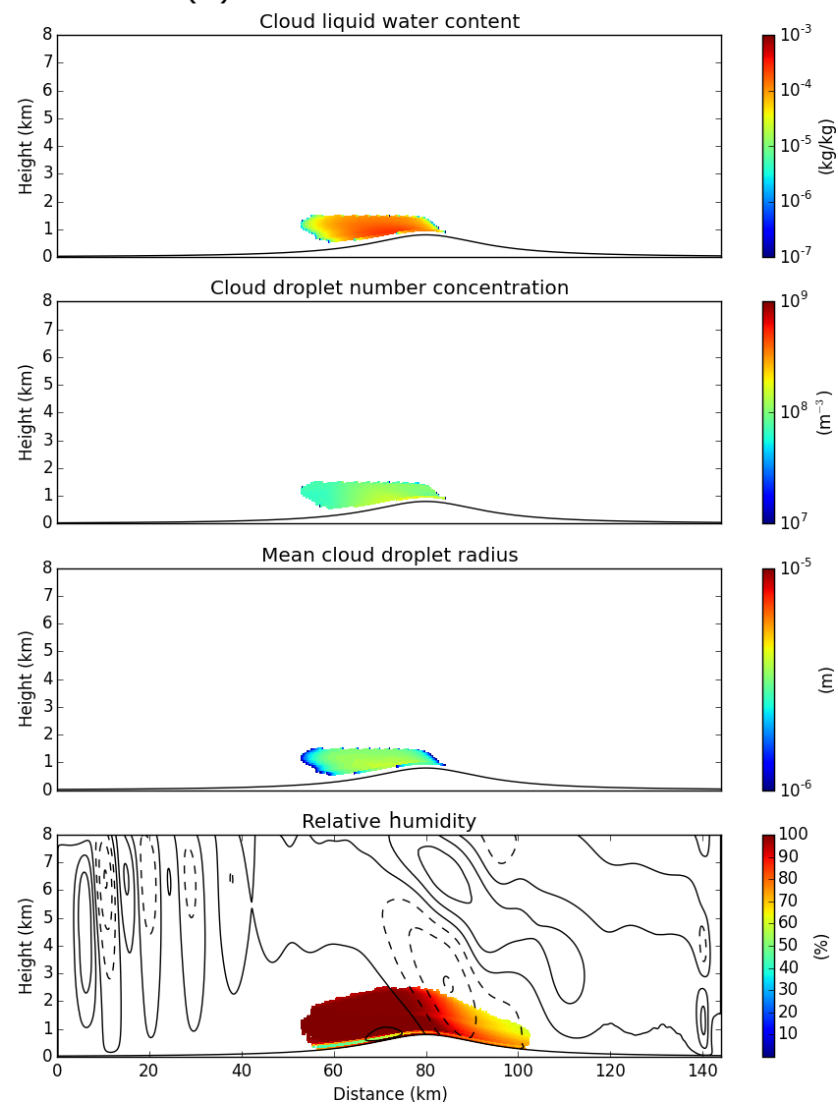

Figure 5. Domain mean horizontal cross section of INP number concentrations in each mode (a) and cloud droplet properties (b) for the orographic cloud at $2 \mathrm{~h}$ into the simulation for normal dust concentrations. Dashed horizontal lines represent the temperature limits of the parameterisations. Contours represent the sign of the vertical velocity (solid: positive; dashed: negative).

Given the different dynamical environment of the stratiform case, the resulting INP concentrations, shown in Fig. 6, are quite low and the cloud is only sparsely populated with INPs, particularly in the immersion mode. Although the relative humidity in the mid-troposphere is high (around 60$70 \%$ ) compared to the other profiles shown in Fig. 2, homogeneous freezing and deposition nucleation do not contribute to ice formation. Immersion INP concentrations are several orders of magnitude larger than contact INP concentrations.

The sounding used to initialise this case, shown in Fig. 2, has a strong decrease in moisture at $5.5 \mathrm{~km}(T=248 \mathrm{~K}$, $p=475 \mathrm{hPa}$ ), which inhibits INP formation at colder temperatures. The maximum in the cloud droplet number concentration and size is between 1 and $2 \mathrm{~km}$, which is outside the temperature range of the contact nucleation parameterisation. Therefore, the concentration of contact INPs is reduced due to the lower concentration of smaller cloud droplets in the region of contact freezing.

\section{Temporal evolution of INPs}

The temporal development of the ice phase influences a host of cloud properties, including cloud lifetime, radiative properties, and precipitation amount. Figure 7 shows the evolution of each INP mode over the duration of the idealised heat bubble simulation, where the domain mean concentrations over all latitudes and longitudes are taken. INPs in the contact mode appear in low concentrations after $15 \mathrm{~min}$. The cloud develops rapidly, producing high concentrations of INPs in the immersion- and contact-freezing modes, as well as through homogeneous freezing. Deposition nucleation also plays a role early in the simulation. As the simulation progresses, the initial convective cell dissipates, and after about $2 \mathrm{~h}$ the simulation enters somewhat of a steady state as secondary convection is initiated throughout the domain. Immersion freezing plays less of a role in later stages of the simulation, and all other modes persist with roughly constant concentrations.

The bottom panel shows the domain mean accumulated precipitation for the duration of the simulation. Precipitation is initiated after about $1 \mathrm{~h}$, and there is a break in precipita- 
(a)
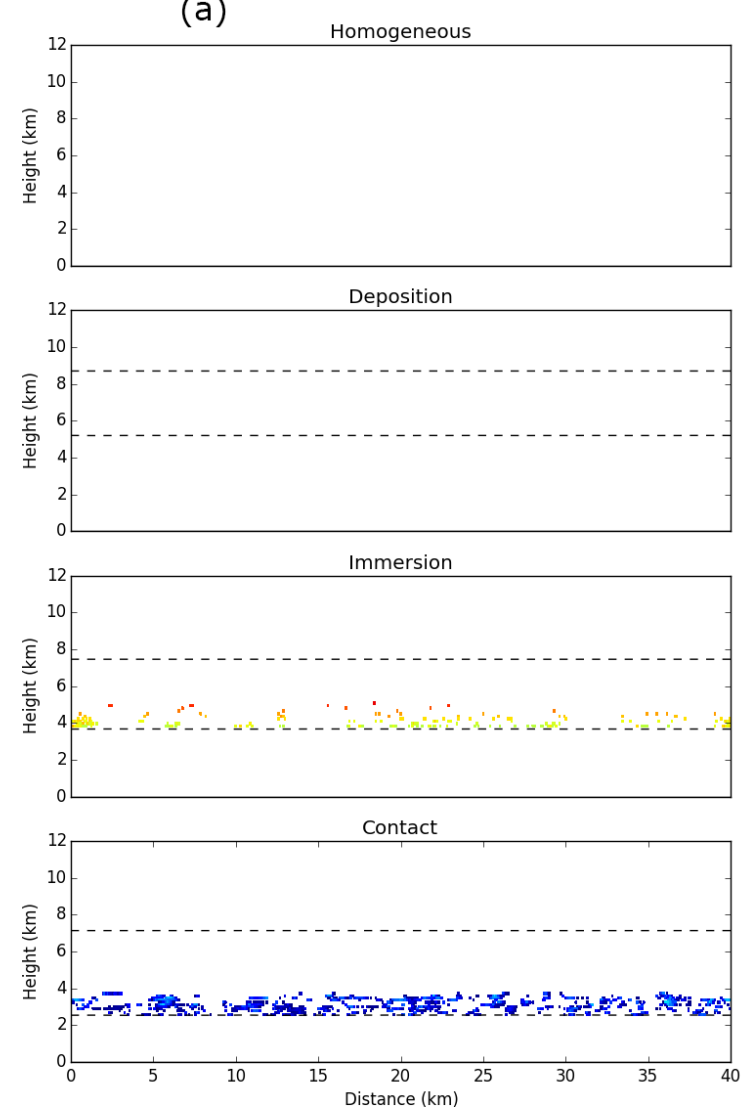

(b)
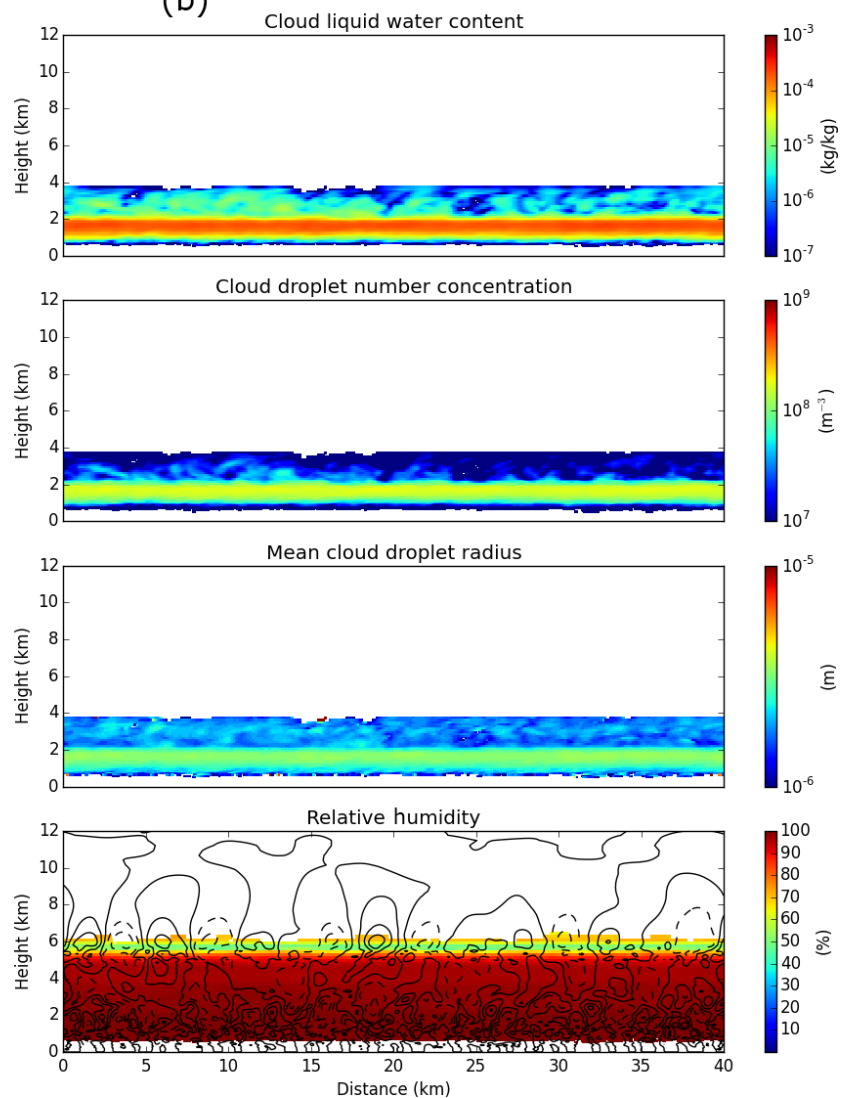

Figure 6. Domain mean horizontal cross section of INP number concentrations in each mode (a) and cloud droplet properties (b) for the stratiform cloud at $3 \mathrm{~h}$ into the simulation for normal dust concentrations. Dashed horizontal lines represent the temperature limits of the parameterisations. Contours represent the sign of the vertical velocity (solid: positive; dashed: negative).

tion coinciding with the dissipation of the main convective cell, with steady precipitation resuming after $2 \mathrm{~h}$. Interestingly, both cases with higher and lower dust aerosol concentrations result in higher precipitation. By the end of the simulation, there is a maximum difference of about $20 \%$ in the total precipitation. Correlation coefficients for the domain mean integrated INP concentrations in each mode and the domain mean total precipitation were calculated, and the correlation coefficients were not significant to any sufficiently high level of confidence. The CCN are not influenced by the dust aerosol distribution used in the INP parameterisations.

As in the previous section, the results in the two convective cases are similar, with the temporal evolution of the INPs in the semi-idealised deep convective case closely mirroring the evolution in the idealised heat bubble case, as shown in Fig. 8. In the semi-idealised convective case the evolution of the cloud is notably slower, reaching maximum INP concentrations after $4 \mathrm{~h}$, at which time immersion freezing dominates. Towards the end of the simulation contact freezing becomes more significant. INPs produced at cold temperatures of less than about $-35^{\circ} \mathrm{C}$ reach their maximum late in the simulation, with the greatest contribution from homogeneous freezing.

Precipitation is initiated during the peak in ice formation, between 3.5 and $5.5 \mathrm{~h}$ into the simulation. This time period is when the immersion and contact INP concentrations reach their maximum, and when homogeneous and deposition nucleation begin to play a role. Perturbations to the dust aerosol concentrations give the opposite effect compared to the previous simulation. That is, both cases of lower and higher dust concentrations give slightly less domain mean accumulated precipitation throughout the simulation.

The temporal evolution of the orographic case, shown in Fig. 9, indicates INP production begins in the contact mode soon after initialisation, followed 15 min later by the immersion mode. As the simulation progresses, the cloud gets a few hundred metres deeper, immersion INP concentrations get gradually higher and contact INP concentrations get gradually lower.

The total precipitation in the orographic case is much lower than the previous two cases. Here, precipitation begins after $0.5 \mathrm{~h}$ and is light and steady for the duration of the simulation. In contrast to the previous cases, the changes in 


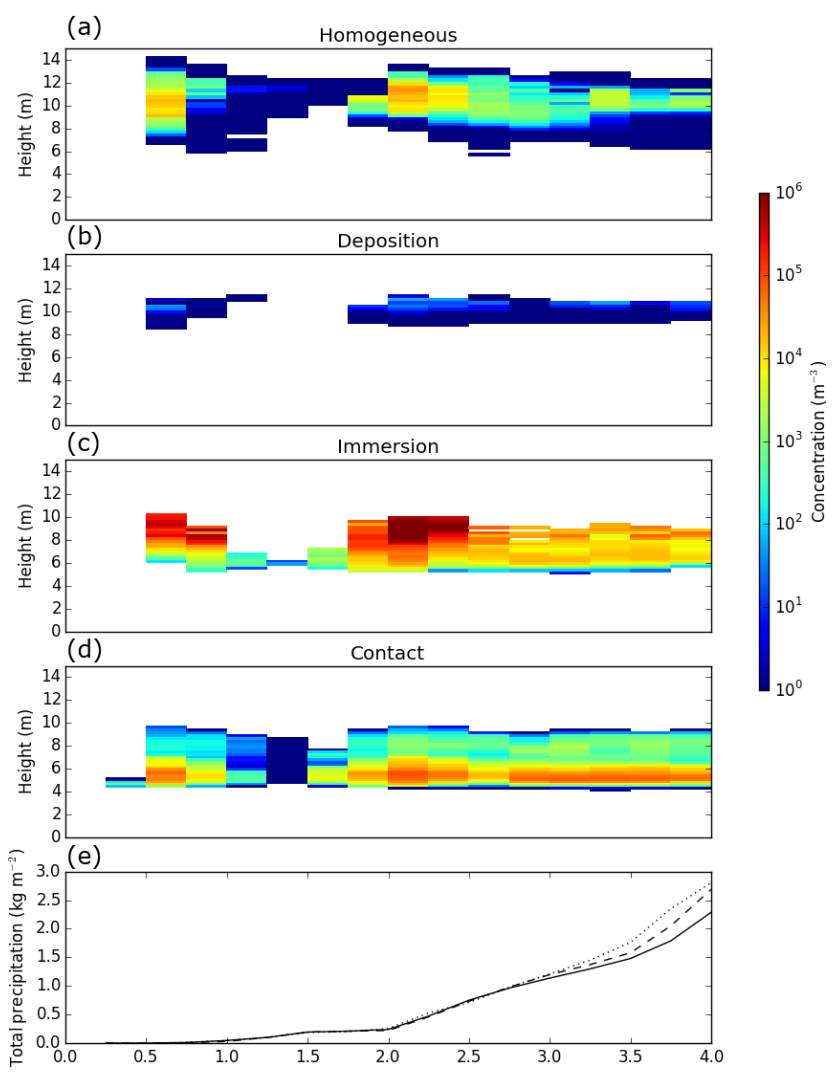

Figure 7. (a-d) Temporal evolution of INP number concentrations in each mode for the heat bubble convective cloud for normal dust concentrations. Panel (e) shows total precipitation. The dashed (dotted) line is for the high (low) aerosol simulation.

the aerosol concentrations give a systematic change in accumulated precipitation, where higher aerosol concentrations result in higher precipitation, and vice versa. The difference in accumulated precipitation at the end of the simulation is around $\pm 10 \%$.

The initial development of the stratiform cloud is similar to that of the other cases, where contact INPs are produced first, followed by immersion mode INPs, as shown in Fig. 10. The contact mode develops slowly over the whole simulation, and is limited to low concentrations. Immersion INPs are produced later, but with higher average concentrations, and the cloud is stable for the duration of the simulation.

For the stratiform case, the precipitation is the lowest amongst all the cases. The simulation with higher dust concentrations shows about $25 \%$ more precipitation, despite minimal changes in droplet size and number concentration. The simulation with lower dust concentrations has a negligible impact.

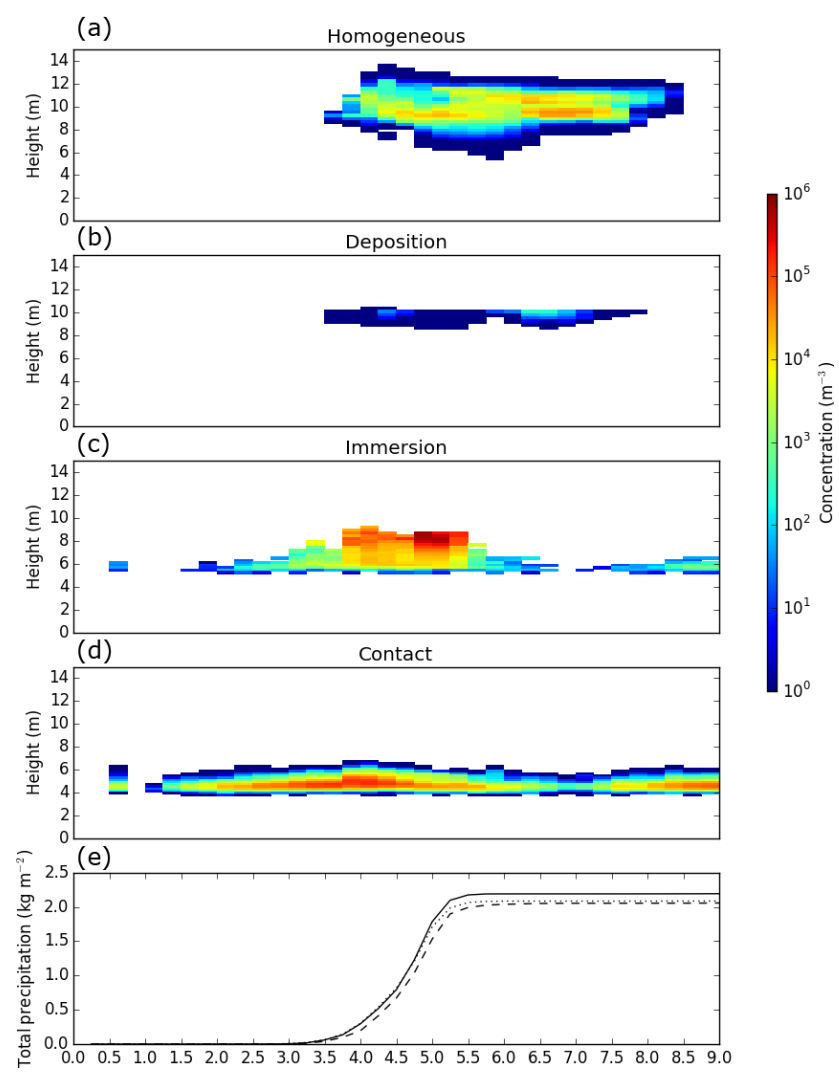

Figure 8. (a-d) Temporal evolution of INP number concentrations in each mode for the semi-idealised deep convective cloud for normal dust concentrations. Panel (e) shows total precipitation. The dashed (dotted) line is for the high (low) aerosol simulation.

\section{Domain mean INPs}

The results thus far are strikingly consistent: immersion and contact freezing dominate at varying times in the simulations, and in the convective cases, homogeneous freezing dominates in the cirrus regime. To quantify this further, Table 1 shows the spatial and temporal mean INP concentrations in each mode, including homogeneous freezing, along with the relative contribution to the total INP concentrations. The aerosol sensitivity simulations for each case are also shown, with $-(+)$ indicating lower (higher) dust aerosol concentrations. Furthermore, the contribution of each mode until the onset of precipitation $\left(>0.05 \mathrm{~kg} \mathrm{~m}^{-2}\right)$ is shown. The concentrations quoted here are domain-wide averages, meaning non-cloudy grid points are included, in order to not bias the results towards short-lived, high INP concentrations.

This confirms that immersion freezing is clearly the dominant INP production mechanism in all cases. Contact freezing plays a significant role in most simulations, accounting for up to one-third of the total INP concentration in the simulation with normal aerosol concentrations. In the convective cases, homogeneous freezing contributes most at cirrus temperatures, and deposition nucleation plays little role. 


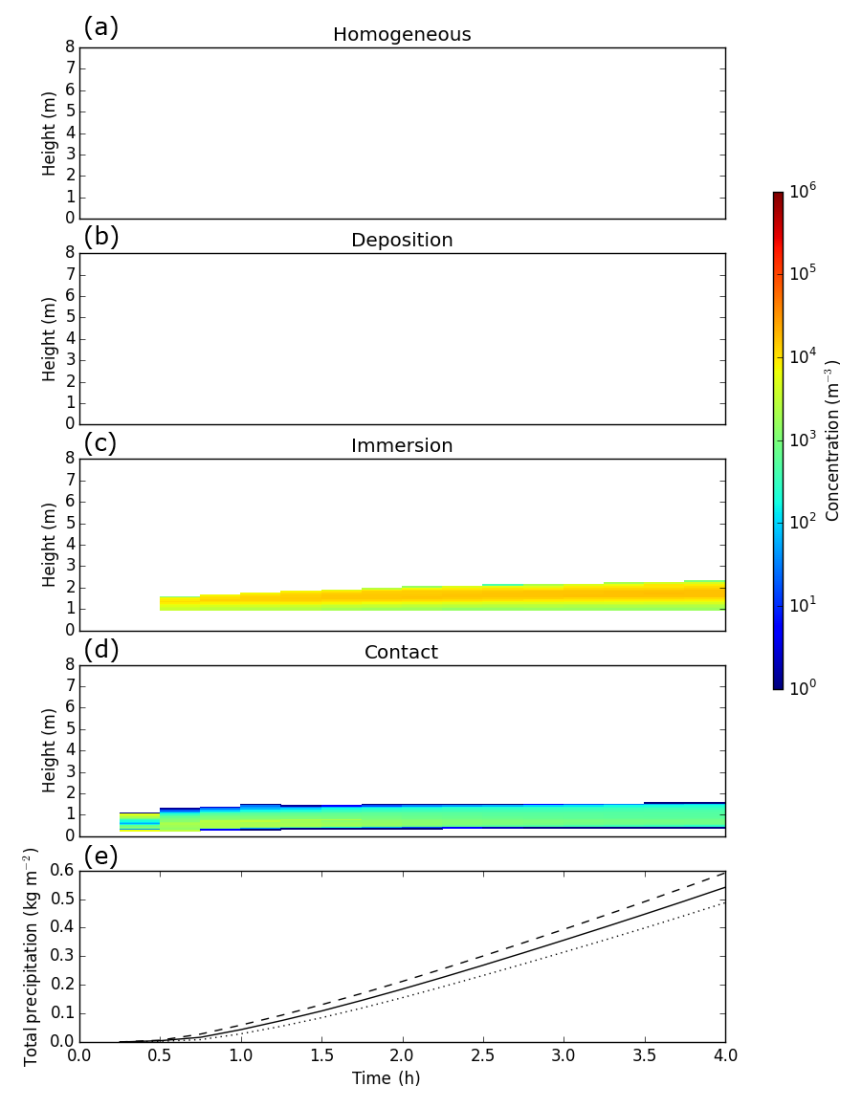

Figure 9. (a-d) Temporal evolution of INP number concentrations in each mode for the orographic cloud for normal dust concentrations. Panel (e) shows total precipitation. The dashed (dotted) line is for the high (low) aerosol simulation.

Leading up to the onset of precipitation, contact ice nucleation plays a dominant role in the semi-idealised convective case and the orographic cloud case. This is since contact nucleation is often the first ice formation mechanism activated, and in these two simulations it contributes significantly at early stages of cloud formation. In the other two cases, immersion freezing contributes only slightly more than the simulations with normal aerosol concentrations.

\section{Discussion}

The INAS density for immersion freezing depends inverse exponentially on temperature. At temperatures of around $248 \mathrm{~K}$, in the middle of the temperature range for the Niemand et al. (2012) parameterisation, the INAS density approaches $10^{10} \mathrm{~m}^{-2}$. This should give an activated fraction of around $0.1(0.95)$ for dust aerosols with radius 1 (5) $\mu \mathrm{m}$. Given that most dust aerosols are much larger than $1 \mu \mathrm{m}$, immersion freezing is efficient in these simulations.

According to Hande et al. (2017), the contact-freezing parameterisation depends primarily on aerosol and droplet sizes. These authors show that the highest contact-freezing

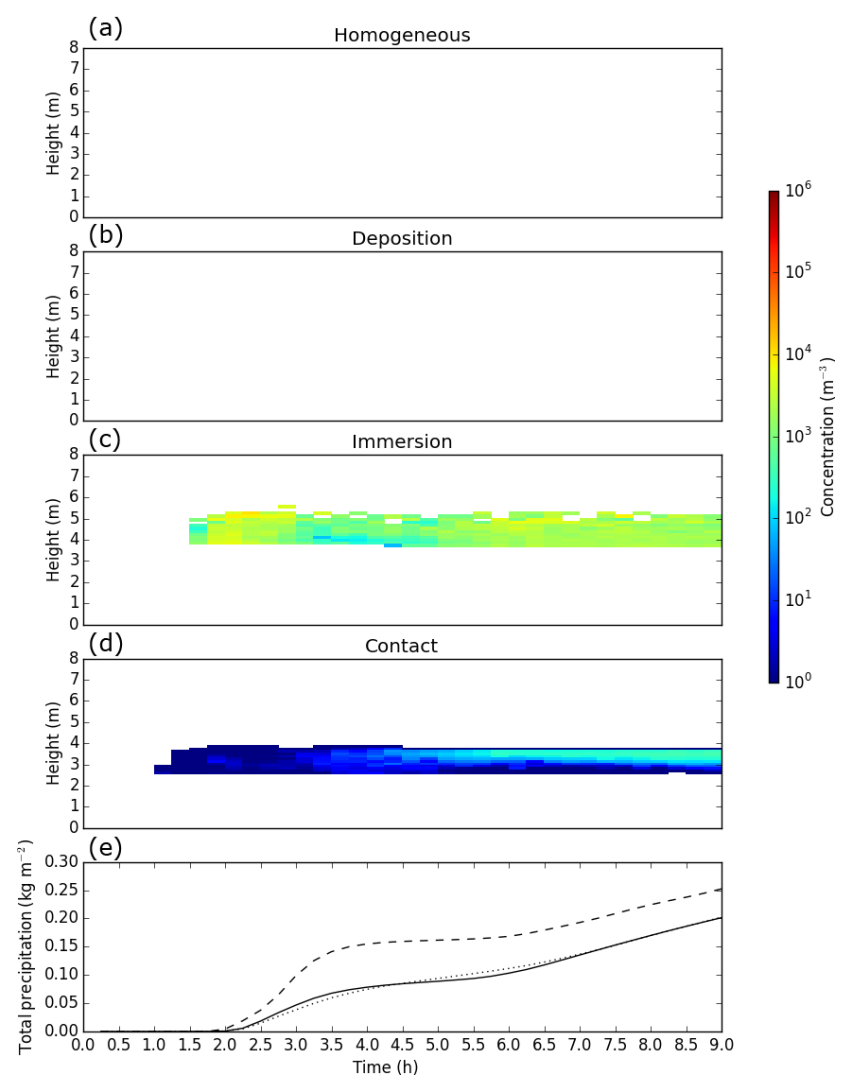

Figure 10. (a-d) Temporal evolution of INP number concentrations in each mode for the stratiform cloud for normal dust concentrations. Panel (e) shows total precipitation. The dashed (dotted) line is for the high (low) aerosol simulation.

rates are obtained when large aerosol particles $(\gtrsim 0.3 \mu \mathrm{m})$ interact with large cloud droplets $(\gtrsim 30 \mu \mathrm{m})$. Only at the very largest sizes is the frozen fraction 1 . In these simulations, droplets are mostly smaller than $20 \mu \mathrm{m}$, resulting in a contact nucleation rate orders of magnitudes smaller than the maximum possible.

Deposition nucleation as parameterised by Steinke et al. (2015) depends inverse exponentially on temperature and exponentially on ice supersaturation. However, it is tightly constrained by observations, such that it is only active at ice supersaturated conditions within a $24 \mathrm{~K}$ temperature window. This strongly limits the number of deposition INPs produced in the simulations. The homogeneous freezing parameterisation, on the other hand, is not as tightly constrained and therefore dominates INP production at cold temperatures.

Some studies do suggest that, in the presence of large aerosol concentrations, homogeneous freezing could be inhibited by heterogeneous INP formation (Phillips et al., 2007). The results presented here show that in the cirrus regime deposition nucleation contributes very little to ice formation, despite the high number concentration of aerosols in this region. The difference between the concentration of ho- 
Table 1. Temporal and spatial mean INP concentrations $\left(\mathrm{m}^{-3}\right)$ for each case. $+(-)$ indicates higher (lower) dust aerosol concentrations, as shown in Fig. 1. The relative contribution $(\%)$ of each mode to the total INP concentrations is shown in parentheses.

\begin{tabular}{|c|c|c|c|c|}
\hline & Hom. & Dep. & Imm. & Con. \\
\hline Heat bubble + & $\begin{array}{l}2.94 \times 10^{2} \\
(0.14)\end{array}$ & $\begin{array}{l}2.25 \times 10^{0} \\
(0.00)\end{array}$ & $\begin{array}{l}2.02 \times 10^{5} \\
(98.07)\end{array}$ & $\begin{array}{l}3.68 \times 10^{3} \\
(1.79)\end{array}$ \\
\hline Heat bubble & $\begin{array}{l}2.77 \times 10^{2} \\
(1.38)\end{array}$ & $\begin{array}{l}3.11 \times 10^{-1} \\
(0.01)\end{array}$ & $\begin{array}{l}1.76 \times 10^{4} \\
(88.31)\end{array}$ & $\begin{array}{l}2.05 \times 10^{3} \\
(10.30)\end{array}$ \\
\hline Heat bubble - & $\begin{array}{l}2.80 \times 10^{2} \\
(8.73)\end{array}$ & $\begin{array}{l}4.11 \times 10^{-2} \\
(0.00)\end{array}$ & $\begin{array}{l}2.09 \times 10^{3} \\
(65.07)\end{array}$ & $\begin{array}{l}8.43 \times 10^{2} \\
(26.20)\end{array}$ \\
\hline $\begin{array}{l}\text { Heat bubble } \\
\text { Precip. onset }\end{array}$ & $\begin{array}{l}3.41 \times 10^{2} \\
(2.52)\end{array}$ & $\begin{array}{l}2.14 \times 10^{-1} \\
(0.00)\end{array}$ & $\begin{array}{l}1.22 \times 10^{4} \\
(89.70)\end{array}$ & $\begin{array}{l}1.05 \times 10^{3} \\
(7.78)\end{array}$ \\
\hline Deep convective + & $\begin{array}{l}3.09 \times 10^{1} \\
(0.12)\end{array}$ & $\begin{array}{l}1.47 \times 10^{-1} \\
(0.00)\end{array}$ & $\begin{array}{l}2.37 \times 10^{4} \\
(90.56)\end{array}$ & $\begin{array}{l}2.43 \times 10^{3} \\
(9.32)\end{array}$ \\
\hline Deep convective & $\begin{array}{l}2.35 \times 10^{2} \\
(6.56)\end{array}$ & $\begin{array}{l}2.75 \times 10^{-1} \\
(0.01)\end{array}$ & $\begin{array}{l}2.11 \times 10^{3} \\
(58.95)\end{array}$ & $\begin{array}{l}1.24 \times 10^{3} \\
(34.48)\end{array}$ \\
\hline Deep convective - & $\begin{array}{l}2.51 \times 10^{2} \\
(28.59)\end{array}$ & $\begin{array}{l}8.73 \times 10^{-2} \\
(0.01)\end{array}$ & $\begin{array}{l}1.95 \times 10^{2} \\
(22.18)\end{array}$ & $\begin{array}{l}4.33 \times 10^{2} \\
(49.22)\end{array}$ \\
\hline $\begin{array}{l}\text { Deep convective } \\
\text { Precip. onset }\end{array}$ & $\begin{array}{l}3.14 \times 10^{-2} \\
(0.00)\end{array}$ & $\begin{array}{l}1.63 \times 10^{-5} \\
(0.00)\end{array}$ & $\begin{array}{l}3.97 \times 10^{1} \\
(3.87)\end{array}$ & $\begin{array}{l}9.88 \times 10^{2} \\
(96.13)\end{array}$ \\
\hline Orographic + & $\begin{array}{l}0 \\
(0)\end{array}$ & $\begin{array}{l}0 \\
(0)\end{array}$ & $\begin{array}{l}1.68 \times 10^{3} \\
(85.84)\end{array}$ & $\begin{array}{l}2.76 \times 10^{2} \\
(14.16)\end{array}$ \\
\hline Orographic & $\begin{array}{l}0 \\
(0)\end{array}$ & $\begin{array}{l}0 \\
(0)\end{array}$ & $\begin{array}{l}1.21 \times 10^{3} \\
(89.91)\end{array}$ & $\begin{array}{l}1.35 \times 10^{2} \\
(10.09)\end{array}$ \\
\hline Orographic - & $\begin{array}{l}0 \\
(0)\end{array}$ & $\begin{array}{l}0 \\
(0)\end{array}$ & $\begin{array}{l}7.65 \times 10^{2} \\
(94.66)\end{array}$ & $\begin{array}{l}4.32 \times 10^{1} \\
(5.34)\end{array}$ \\
\hline $\begin{array}{l}\text { Orographic } \\
\text { Precip Onset }\end{array}$ & $\begin{array}{l}0 \\
(0)\end{array}$ & $\begin{array}{l}0 \\
(0)\end{array}$ & $\begin{array}{l}5.77 \times 10^{2} \\
(73.50)\end{array}$ & $\begin{array}{l}2.08 \times 10^{2} \\
(26.50)\end{array}$ \\
\hline Stratiform + & $\begin{array}{l}0 \\
(0)\end{array}$ & $\begin{array}{l}0 \\
(0)\end{array}$ & $\begin{array}{l}6.21 \times 10^{2} \\
(99.97)\end{array}$ & $\begin{array}{l}1.81 \times 10^{-1} \\
(0.03)\end{array}$ \\
\hline Stratiform & $\begin{array}{l}0 \\
(0)\end{array}$ & $\begin{array}{l}0 \\
(0)\end{array}$ & $\begin{array}{l}1.87 \times 10^{2} \\
(97.54)\end{array}$ & $\begin{array}{l}4.73 \times 10^{0} \\
(2.46)\end{array}$ \\
\hline Stratiform - & $\begin{array}{l}0 \\
(0)\end{array}$ & $\begin{array}{l}0 \\
(0)\end{array}$ & $\begin{array}{l}1.85 \times 10^{2} \\
(99.92)\end{array}$ & $\begin{array}{l}1.49 \times 10^{-1} \\
(0.08)\end{array}$ \\
\hline $\begin{array}{l}\text { Stratiform } \\
\text { Precip Onset }\end{array}$ & $\begin{array}{l}0 \\
(0)\end{array}$ & $\begin{array}{l}0 \\
(0)\end{array}$ & $\begin{array}{l}1.76 \times 10^{2} \\
(99.95)\end{array}$ & $\begin{array}{l}8.37 \times 10^{-2} \\
(0.05)\end{array}$ \\
\hline
\end{tabular}

mogeneously formed ice and deposition nucleation INP is several orders of magnitude. This indicates that deposition nucleation is not suppressing homogeneous freezing in the simulated cases.

The effect of perturbations in the dust aerosol concentrations is complex and depends on the cloud type. In the convective cases, increasing aerosol concentrations increases the relative contribution of immersion freezing by an almost equivalent amount. The other freezing modes then compensate, resulting in a decrease in their relative contribution. The opposite is also true. Decreasing concentrations of dust aerosol decreases the contribution of immersion freezing, while increasing the relative contribution of the other modes. Indeed, in the idealised heat bubble case, contact freezing becomes the dominant mode in low aerosol conditions. There are, however, two exceptions where complex non-monotonic responses are evident: in deposition nucleation in the deep convective simulation, and in contact freezing in the stratiform case.

A natural question arises as to the sensitivity to the thermodynamic profile used to initialise the simulations, and hence how generalisable the results are. Given that the two convective cases, which had vastly different thermodynamic profiles, produced very similar results, this suggests the relative contribution of the ice nucleation modes is more or less insensitive to the initial conditions in these cases. Notice that the droplet properties of both convective cases, shown in Figs. 1, 3, and 4, are very similar. Fan et al. (2017), however, show that thermodynamics contributes significantly to cloud microphysical processes for orographic mixed-phase clouds. This suggests the sensitivity for non-convectively forced clouds could be larger. 
The stratiform case study represents the only cloud type in this study which is weakly forced. Despite high levels of moisture above the main inversion, the conditions for homogeneous freezing or deposition nucleation were not met in this simulation. There is a fundamental difference between cirrus produced in different dynamical environments. In the convective cases, liquid water is lifted from the mixed-phase regime to colder temperatures, where it freezes. Since the stratiform case is weakly forced, the origin of the moisture is from higher altitudes. These two categories are known as either "liquid origin cirrus" or "in situ cirrus" (Krämer et al., 2016; Luebke et al., 2016). Since the stratiform cloud investigated here has no cirrus, the dominant ice-forming mechanism for this so-called "in situ cirrus" remains an open question.

A few of the assumptions built into the simulations may influence the results presented. The even separation of immersed and interstitial aerosols will most likely cause an overestimate of contact freezing, in particular in the updraught where the supersaturation is the highest, and immersion freezing could be more dominant. Unprocessed dust has low CCN activity, whereas aged dust is more likely to be immersed (Kumar et al., 2011). The effect of this uncertainty is, however, expected to be small compared to the ordersof-magnitude difference in INP number concentrations between the different nucleation modes. Also, neglecting contact freezing and aerosol-dependent immersion freezing of rain droplets should not have a large influence on the dominant freezing mode in these simulations; however, it could affect the precipitation formation (Paukert et al., 2017).

A final consideration concerning the aerosol species needs to be made. Aerosol composition has a large influence on nucleation ability in different temperature and supersaturation regimes. Hoose and Möhler (2012) show that biological aerosols have a high onset temperature in the immersion mode, and given that certain biological aerosols can have large INAS densities at these warm temperatures (Murray et al., 2012), this could represent an important contributor to ice nucleation. A similar distinction between different dust species could also be made, since soil dust, for example, is more ice active in the immersion mode (Steinke et al., 2016). Whether this has a significant impact on the dominant ice nucleation mode remains to be investigated.

\section{Conclusions}

A number of high-resolution modelling case studies are presented in order to systematically investigate which ice nucleation modes dominate for a number of typical cloud types. The results indicate that immersion freezing dominates in all cases. Contact nucleation plays a significant role in most simulations, accounting for between about 2 and $33 \%$ of total INP concentrations under the reference aerosol conditions. Deposition nucleation only contributes a fraction of a percent in the convective cases, and homogeneous freezing accounts for up to $6 \%$ of total ice crystal concentrations. However, in the non-convective cases, no INPs were produced in the cirrus regime.

In the later stages of the convective clouds, homogeneous freezing became more important, and contact freezing dominated at warm temperatures. INP formation in the orographic and stratiform case reached a steady state soon after the formation of the cloud. The occurrence of precipitation is not correlated with any one ice nucleation mode, instead occurring at the same time as multiple ice nucleation modes, including homogeneous nucleation.

Since the results from the two convective cases were quite similar, this suggests ice nucleation could be insensitive to thermodynamical conditions in these cases. The main consequence of the much higher CAPE in the heat bubble case, compared to the semi-idealised deep convective case, was faster cloud development.

For the convective cases, perturbation in aerosol concentrations produced proportional changes in the relative contribution of immersion-freezing INPs. The relative contribution of the other modes decreased for increased dust concentrations. In particular, homogeneous freezing is nearly entirely suppressed. In contrast, for the orographic case, the relative contribution of contact ice nucleation increased under higher aerosol concentrations, and immersion freezing decreased. In the stratiform case, all aerosol perturbations produced relatively more immersion-freezing INPs, and fewer contact INPs. This indicates aerosol conditions have a complex influence on the dominant ice nucleation mode.

The response of the precipitation to perturbations in aerosol concentrations is also complex, and each case exhibits a different response. For the heat bubble, increasing and decreasing aerosol concentrations lead to an increase in precipitation. The opposite is true for the semi-idealised deep convective cloud, where both aerosol perturbations result in a decrease in precipitation. The orographic case shows proportional changes in precipitation in response to changing the aerosol concentrations, and in the stratiform case the higher aerosol concentrations produce more precipitation, with lower concentrations having no impact. This indicates that, although aerosol concentration plays a role in modifying precipitation, it is not the sole contributor. There could also be complex feedbacks present, where changes in dust aerosol concentrations change the amount of ice produce, which in turn changes the latent heat release. This would have an impact on both the amount of liquid condensate and also the dominant ice nucleation mechanism.

Data availability. The data are available from the corresponding authors upon request. 
Competing interests. The authors declare that they have no conflict of interest.

Special issue statement. This article is part of the special issue "Results from the ice nucleation research unit (INUIT) (ACP/AMT inter-journal SI)". It is not associated with a conference.

Acknowledgements. This work was funded by the Deutsche Forschungsgemeinschaft through the research unit INUIT-2 (FOR 1525, HO4612/1-2). The authors would like to gratefully acknowledge Christian Barthlott (KIT) and Lulin Xue (NCAR) for assistance with the model configuration.

The article processing charges for this open-access publication were covered by a Research

Centre of the Helmholtz Association.

Edited by: Allan Bertram

Reviewed by: two anonymous referees

\section{References}

Ansmann, A., Tesche, M., Seifert, P., Althausen, D., Engelmann, R., Fruntke, J., Wandinger, U., Mattis, I., and Müller, D.: Evolution of the ice phase in tropical altocumulus: SAMUM lidar observations over Cape Verde, J. Geophys. Res.-Atmos., 114, D17208, https://doi.org/10.1029/2008JD011659, 2009.

Barthlott, C. and Hoose, C.: Spatial and temporal variability of clouds and precipitation over Germany: multiscale simulations across the "gray zone", Atmos. Chem. Phys., 15, 12361-12384, https://doi.org/10.5194/acp-15-12361-2015, 2015.

Carro-Calvo, L., Hoose, C., Stengel, M., and SalcedoSanz, S.: Cloud Glaciation Temperature Estimation from Passive Remote Sensing Data with Evolutionary Computing, J. Geophys. Res.-Atmos., 121, 13591-13608, https://doi.org/10.1002/2016JD025552, 2016.

Cui, Z., Carslaw, K. S., Yin, Y., and Davies, S.: A numerical study of aerosol effects on the dynamics and microphysics of a deep convective cloud in a continental environment, J. Geophys. Res.Atmos., 111, D05201, https://doi.org/10.1029/2005JD005981, 2006.

Cziczo, D. J., Ladino, L., Boose, Y., Kanji, Z. A., Kupiszewski, P., Lance, S., Mertes, S., and Wex, H.: Chapter 8: Measurements of Ice Nucleating Particles and Ice Residuals, Meteorol. Monogr., 58, 8.1-8.13, https://doi.org/10.1175/AMSMONOGRAPHS-D16-0008.1, 2016.

De Boer, G., Morrison, H., Shupe, M., and Hildner, R.: Evidence of liquid dependent ice nucleation in high-latitude stratiform clouds from surface remote sensors, Geophys. Res. Lett., 38, L01803, https://doi.org/10.1029/2010GL046016, 2011.

DeMott, P. H., Prenni, A. J., Liu, X., Kreidenweis, S. M., Petters, M. D., Twohy, C. H., Richardson, M. S., Eidhammer, T., and Rogers, D. C.: Predicting global atmospheric ice nuclei distributions and their impacts on climate, P. Natl. Acad. Sci. USA, 107, 1121711222,2010
DeMott, P. J., Prenni, A. J., McMeeking, G. R., Sullivan, R. C., Petters, M. D., Tobo, Y., Niemand, M., Möhler, O., Snider, J. R., Wang, Z., and Kreidenweis, S. M.: Integrating laboratory and field data to quantify the immersion freezing ice nucleation activity of mineral dust particles, Atmos. Chem. Phys., 15, 393-409, https://doi.org/10.5194/acp-15-393-2015, 2015.

Diehl, K. and Mitra, S. K.: New particle-dependent parameterizations of heterogeneous freezing processes: sensitivity studies of convective clouds with an air parcel model, Atmos. Chem. Phys., 15, 12741-12763, https://doi.org/10.5194/acp-15-127412015, 2015.

Durant, A. J. and Shaw, R. A.: Evaporation freezing by contact nucleation inside-out, Geophys. Res. Lett., 32, L20814, https://doi.org/10.1029/2005GL024175, 2005.

Fan, J., Leung, L. R., Rosenfeld, D., and DeMott, P. J.: Effects of cloud condensation nuclei and ice nucleating particles on precipitation processes and supercooled liquid in mixedphase orographic clouds, Atmos. Chem. Phys., 17, 1017-1035, https://doi.org/10.5194/acp-17-1017-2017, 2017.

Field, P., Heymsfield, A., Shipway, B., DeMott, P., Pratt, K., Rogers, D., Stith, J., and Prather, K.: Ice in clouds experiment-layer clouds. Part II: Testing characteristics of heterogeneous ice formation in lee wave clouds, J. Atmos. Sci., 69, 1066-1079, 2012.

Hande, L. B., Engler, C., Hoose, C., and Tegen, I.: Seasonal variability of Saharan desert dust and ice nucleating particles over Europe, Atmos. Chem. Phys., 15, 4389-4397, https://doi.org/10.5194/acp-15-4389-2015, 2015.

Hande, L. B., Hoose, C., and Barthlott, C.: Aerosol and droplet dependent contact freezing: Parameterisation development and case study, J. Atmos. Sci., 74, 2229-2245, https://doi.org/10.1175/JAS-D-16-0313.1, 2017.

Hiranuma, N., Paukert, M., Steinke, I., Zhang, K., Kulkarni, G., Hoose, C., Schnaiter, M., Saathoff, H., and Möhler, O.: A comprehensive parameterization of heterogeneous ice nucleation of dust surrogate: laboratory study with hematite particles and its application to atmospheric models, Atmos. Chem. Phys., 14, 13145-13158, https://doi.org/10.5194/acp-14-131452014, 2014.

Hoose, C. and Möhler, O.: Heterogeneous ice nucleation on atmospheric aerosols: a review of results from laboratory experiments, Atmos. Chem. Phys., 12, 9817-9854, https://doi.org/10.5194/acp-12-9817-2012, 2012.

Hoose, C., Kristjánsson, J. E., Chen, J.-P., and Hazra, A.: A classical-theory-based parameterization of heterogeneous ice nucleation by mineral dust, soot, and biological particles in a global climate model, J. Atmos. Sci., 67, 2483-2503, 2010.

Houze, R. A.: Cloud dynamics, in: International Geophysics, Vol. 104, Academic Press/Elsevier, Oxford, UK, 2014.

Jeffery, C. and Austin, P.: Homogeneous nucleation of supercooled water: Results from a new equation of state, J. Geophys. Res., 102, 25-269, 1997.

Kanji, Z. A., Ladino, L. A., Wex, H., Boose, Y., BurkertKohn, M., Cziczo, D. J., and Krämer, M.: Chapter 1: Overview of Ice Nucleating Particles, Meteorol. Monogr., 58, 1.1-1.33, https://doi.org/10.1175/AMSMONOGRAPHS-D16-0006.1, 2017.

Koop, T. and Murray, B. J.: A physically constrained classical description of the homogeneous nucleation of ice in water, J. Chem. Phys., 145, 211915, https://doi.org/10.1063/1.4962355, 2016. 
Krämer, M., Rolf, C., Luebke, A., Afchine, A., Spelten, N., Costa, A., Meyer, J., Zöger, M., Smith, J., Herman, R. L., Buchholz, B., Ebert, V., Baumgardner, D., Borrmann, S., Klingebiel, M., and Avallone, L.: A microphysics guide to cirrus clouds - Part 1: Cirrus types, Atmos. Chem. Phys., 16, 3463-3483, https://doi.org/10.5194/acp-16-3463-2016, 2016.

Kumar, P., Sokolik, I. N., and Nenes, A.: Measurements of cloud condensation nuclei activity and droplet activation kinetics of fresh unprocessed regional dust samples and minerals, Atmos. Chem. Phys., 11, 3527-3541, https://doi.org/10.5194/acp-113527-2011, 2011.

Ladino Moreno, L. A., Stetzer, O., and Lohmann, U.: Contact freezing: a review of experimental studies, Atmos. Chem. Phys., 13, 9745-9769, https://doi.org/10.5194/acp-13-9745-2013, 2013.

Li, W., Li, P., Sun, G., Zhou, S., Yuan, Q., and Wang, W.: Cloud residues and interstitial aerosols from non-precipitating clouds over an industrial and urban area in northern China, Atmos. Environ., 45, 2488-2495, 2011.

Luebke, A. E., Afchine, A., Costa, A., Grooß, J.-U., Meyer, J., Rolf, C., Spelten, N., Avallone, L. M., Baumgardner, D., and Krämer, M.: The origin of midlatitude ice clouds and the resulting influence on their microphysical properties, Atmos. Chem. Phys., 16, 5793-5809, https://doi.org/10.5194/acp-16-5793-2016, 2016.

Murray, B., O'Sullivan, D., Atkinson, J., and Webb, M.: Ice nucleation by particles immersed in supercooled cloud droplets, Chem. Soc. Rev., 41, 6519-6554, 2012.

Nagare, B., Marcolli, C., Welti, A., Stetzer, O., and Lohmann, U.: Comparing contact and immersion freezing from continuous flow diffusion chambers, Atmos. Chem. Phys., 16, 8899-8914, https://doi.org/10.5194/acp-16-8899-2016, 2016.

Niehaus, J. and Cantrell, W.: Contact freezing of water by salts, J. Phys. Chem. Lett., 6, 3490-3495, 2015.

Niemand, M., Möhler, O., Vogel, B., Vogel, H., Hoose, C., Connolly, P., Klein, H., Bingemer, H., DeMott, P., Skrotzki, J., and Leisner, T.: A particle-surface-area-based parameterization of immersion freezing on desert dust particles, J. Atmos. Sci., 69, 3077-3092, 2012.

Paukert, M. and Hoose, C.: Modeling immersion freezing with aerosol-dependent prognostic ice nuclei in Arctic mixed-phase clouds, J. Geophys. Res.-Atmos., 119, 9073-9092, 2014.

Paukert, M., Hoose, C., and Simmel, M.: Redistribution of ice nuclei between cloud and rain droplets: Parameterization and application to deep convective clouds, J. Adv. Model. Earth Syst., 9, 514-535, https://doi.org/10.1002/2016MS000841, 2017.

Phillips, V. T., Donner, L. J., and Garner, S. T.: Nucleation processes in deep convection simulated by a cloud-system-resolving model with double-moment bulk microphysics, J. Atmos. Sci., 64, 738$761,2007$.

Rogers, D. C., DeMott, P. J., Kreidenweis, S. M., and Chen, Y.: Measurements of ice nucleating aerosols during SUCCESS, Geophys. Res. Lett., 25, 1383-1386, 1998.
Schättler, U., Doms, G., and Schraff, C.: A description of the nonhydrostatic regional COSMO-model. Part VII: user's guide, Deutscher Wetterdienst Rep. COSMO-Model 4, Deutscher Wetterdienst, Offenbach, Germany, 221 pp., 2008.

Seifert, A. and Beheng, K.: A two-moment cloud microphysics parameterization for mixed-phase clouds. Part 1: Model description, Meteorol. Atmos. Phys., 92, 45-66, 2006.

Spichtinger, P. and Cziczo, D. J.: Impact of heterogeneous ice nuclei on homogeneous freezing events in cirrus clouds, J. Geophys. Res.-Atmos., 115, D14208, https://doi.org/10.1029/2009JD012168, 2010.

Steinke, I., Hoose, C., Möhler, O., Connolly, P., and Leisner, T.: A new temperature- and humidity-dependent surface site density approach for deposition ice nucleation, Atmos. Chem. Phys., 15, 3703-3717, https://doi.org/10.5194/acp-15-3703-2015, 2015.

Steinke, I., Funk, R., Busse, J., Iturri, A., Kirchen, S., Leue, M., Möhler, O., Schwartz, T., Schnaiter, M., Sierau, B., Toprak, E., Ullrich, R., Ulrich, A., Hoose, C., and Leisner, T.: Ice nucleation activity of agricultural soil dust aerosols from Mongolia, Argentina, and Germany, J. Geophys. Res.-Atmos., 121, 13559_ 13576, https://doi.org/10.1002/2016JD025160, 2016.

Tobo, Y., Prenni, A. J., DeMott, P. J., Huffman, J. A., McCluskey, C. S., Tian, G., Pöhlker, C., Pöschl, U., and Kreidenweis, S. M.: Biological aerosol particles as a key determinant of ice nuclei populations in a forest ecosystem, J. Geophys. Res.-Atmos., 118, 10100-10110, https://doi.org/10.1002/jgrd.50801, 2013.

Ullrich, R., Hoose, C., Möhler, O., Niemand, M., Wagner, R., Höhler, K., Hiranuma, N., Saathoff, H., and Leisner, T.: A new ice nucleation active site parameterization for desert dust and soot, J. Atmos. Sci., 74, 699-717, 2017.

Vali, G., DeMott, P. J., Möhler, O., and Whale, T. F.: Technical Note: A proposal for ice nucleation terminology, Atmos. Chem. Phys., 15, 10263-10270, https://doi.org/10.5194/acp-15-102632015, 2015.

Wang, P., Grover, S., and Pruppacher, H.: On the effect of electric charges on the scavenging of aerosol particles by clouds and small raindrops, J. Atmos. Sci., 35, 1735-1743, 1978.

Weisman, M. L. and Klemp, J. B.: The dependence of numerically simulated convective storms on vertical wind shear and buoyancy, Mon. Weather Rev., 110, 504-520, 1982.

Westbrook, C. D. and Illingworth, A. J.: Evidence that ice forms primarily in supercooled liquid clouds at temperatures $>-27^{\circ} \mathrm{C}$, Geophys. Res. Lett., 38, L14808, https://doi.org/10.1029/2011GL048021, 2011.

Wiacek, A. and Peter, T.: On the availability of uncoated mineral dust ice nuclei in cold cloud regions, Geophys. Res. Lett., 36, L17801, https://doi.org/10.1029/2009GL039429, 2009. 